\title{
Control in Virtual Learning Communities: An Investigation from the Views of Trust and Effectiveness Uncertainty
}

\author{
Ying-Wei Shih
}

\begin{abstract}
This study investigates how control, through trust and effectiveness uncertainty, affects learners' willingness to depend on a virtual learning community (VLC). Three variables, perceived accreditation, perceived feedback, and perceived cooperative norms, were incorporated to represent different types of control. The research hypotheses were tested on a sample of 264 survey participants using Partial Least Squares (PLS). The results indicate that cooperative norms and feedback engender trust in the VLC, that accreditation and cooperative norms reduce effectiveness uncertainty, and that trust increases learners' willingness to depend on VLC. The relationships between trust and effectiveness uncertainty, between effectiveness uncertainty and willingness to depend, between feedback and effectiveness uncertainty, and between accreditation and trust are unconfirmed.
\end{abstract}

Index Terms-Control, effectiveness uncertainty, trust, virtual learning community.

\section{INTRODUCTION}

Virtual learning communities (VLC) based on computer-mediated communication are not as robust as traditional face-to-face communities [1]; control accordingly becomes a crucial issue. With a focus on VLC, this study attempts to draw on control theory [2], [3] and institution-based trust theory [4] to answer the following questions: (1) what is the role of control in VLC? and (2) what are the relationships between control, trust, effectiveness uncertainty, and learner behavior in VLC? In the following section, the author puts forward hypotheses to delineate how particular types of control, mediated by trust and effectiveness uncertainty, affect learners' intention to rely on VLC.

\section{Conceptual DeVelopment}

This study defines control as "efforts by the VLC administration or members to increase the probability that members will behave as expected so as to achieve the goal of this community" following Das [5] and Tannebaum [6]. The early organizational theorists classified control into two independent modes: behavior and output (or outcome)

Manuscript received November 2, 2012; revised January 11, 2013. This work was partially supported by the National Science Council of Taiwan under contract number NSC 96-2416-H-018-009.

Ying-Wei Shih is with the Department of Information Management, National Changhua University of Education, Changhua, Taiwan (e-mail: ywshih@im.ncue.edu.tw).
[2]. This primitive typology was further modified by adding clan control to represent the social aspect of control [3]. According to Pavlou [4], who proposed five institutional structures: monitoring, accreditation, legal bonds, feedback, and cooperative norms to regulate behavior and build trust, instances of those modes of control applicable to VLC include: accreditation (output control), feedback (behavior control), and cooperative norms (clan control).

This study also defines trust in the VLC as "a learner's subjective belief that VLC members will behave as trustworthily as expected" following Pavlou and Gefen [7] and perceived effectiveness uncertainty as "a learner's perception that he or she is unable to accurately predict the attainment of positive effects from taking part in a VLC" following Milliken [8].

\section{A. Perceived Accreditation}

Accreditation in a VLC represents output control. Following Pavlou [4], this study defines perceived accreditation as the extent to which learners believe that accreditation is effective in assuring them of quality content.

Accreditation is a key element in a normative environment [9], and people usually trust something that is accredited [4]. If learners in a VLC feel that everything they access is quality, they will appreciate the functioning of an effective accreditation process and consider that other participants are capable contributors. As a result, they will trust the VLC and be more confident of gaining positive effects from interacting with those VLC participants.

H1a: Perceived accreditation positively influences learners' trust in the VLC

H1b: Perceived accreditation negatively influences learners' perceived effectiveness uncertainty

\section{B. Perceived Feedback}

Feedback represents behavior control. Following Pavlou [4] and Pavlou and Gefen [7], this study defines perceived feedback as the extent to which learners believe that the feedback mechanism is effective in providing accurate information about past behavior of VLC members. According to Pavlou, a feedback mechanism aims at self-regulation of behavior by giving signals about other VLC participants' reputation to learners while creating incentives for those participants to behave well in order to earn a good reputation. This implies that the feedback mechanism is a factor in breeding trust in the VLC.

$\mathrm{H} 2 \mathrm{a}$ : Perceived feedback positively influences learners' trust in the VLC 
Many researchers have argued that searching for information is a strategy widely adopted by human beings in dealing with uncertainty [10]. A feedback mechanism is essential for reducing learners' perceived level of exchange-specific uncertainty. Pavlou's signal-incentive perspective can also be used to predict a favorable outcome of exchange.

H2b: Perceived feedback negatively influences learners' perceived effectiveness uncertainty

\section{Perceived Cooperative Norms}

Cooperative norms represent value-based clan control. Following Pavlou [4], this study defines perceived cooperative norms as the extent to which learners believe that VLC members proactively and frequently share information and knowledge in learning interactions.

Cooperative norms in a VLC promote learning collaboration. By acting upon these norms, learners send a message of being benevolent and responsible to others; besides, learners will deem that other members are of good faith if they believe that cooperative norms have been set and become part of the character of those members [4], resulting in the growth of trust in the VLC. Also, cooperation brings synergy; learners' perceived cooperative norms will help inspire their confidence in obtaining positive effects.

H3a: Perceived cooperative norms positively influence learners' trust in the VLC

$\mathrm{H} 3 \mathrm{~b}$ : Perceived cooperative norms negatively influence learners' perceived effectiveness uncertainty

\section{Trust and Perceived Effectiveness Uncertainty}

Research has recognized the importance of trust as an effective mental shortcut to diminish uncertainty perception [11]. In a co-working relationship in which trust exists, people are not necessarily worried about opportunistic or undesirable conduct of others that may inhibit the accomplishment of the shared goal [10], [12]. In other words, with belief in others' trustworthiness, people will be more confident of the realization of positive effects from co-operation.

H4: Trust in the VLC negatively influences learners' perceived effectiveness uncertainty

\section{E. Trust and Willingness to Depend}

Research into economically based online exchange has demonstrated that trust increases transaction intention (e.g., [12]-[14]). Similar results have been found in other studies regarding non-transactional relationships, in which trust was also found to be a determinant of various behavior intentions, e.g., adoption of particular IT-based services [15], desire to get and give information [16], willingness to depend, and sharing of personal information [17]. Therefore,

H5: Trust in the VLC positively influences learner's willingness to depend on the VLC

\section{F. Perceived Effectiveness Uncertainty and Willingness to Depend}

Bordia et al. [18] have observed that uncertainty leads to "an aversive state" and that empirical evidence supports a positive relationship between uncertainty and a person's anxiety, stress, and psychological strain. Learners who take part in a VLC usually expect a positive outcome. Perceived uncertainty of gaining positive effects prompts an adverse psychological condition or belief against interacting with VLC members, which leads to a detrimental influence on the willingness to depend on the VLC.

H6: Perceived effectiveness uncertainty negatively influences learners' willingness to depend on the VLC

\section{G. Control Variable}

Many studies have found that individual propensity to trust affects trust [7], [12], [15]; this study thus controls for its effect on trust in the VLC.

\section{ReseARCH Methodology}

Table I shows the research constructs and sources of items used to measure these constructs. All measurement items are seven-point scales ranging either from "very certain" (1) to "very uncertain" (7) for the construct of perceived effectiveness uncertainty, or from "strongly disagree" (1) to "strongly agree" (7) for the other constructs.

TABLE I: RESEARCH CONSTRUCTS AND ITEM SOURCES

\begin{tabular}{ll}
\hline \hline Constructs & Sources of measurement items \\
\hline Trust in the VLC (TIV) & {$[7],[12]$} \\
Perceived effectiveness uncertainty & Self-developed (based on \\
(PEU) & Milliken's [8] definition) \\
Willingness to depend (WTD) & {$[19]$} \\
Perceived accreditation (PAC) & {$[4]$} \\
Perceived feedback (PFB) & {$[7]$} \\
Perceived cooperative norms (PCN) & {$[20]$} \\
Propensity to trust (PTT) & {$[12]$} \\
\hline \hline
\end{tabular}

This study collected data using two methods. One of them online recruited experienced VLC participants to the survey; a web-based version of the questionnaire was used to collect the responses. The other one gathered responses from students in a public university in Taiwan via a pencil-and-paper version of the questionnaire. At the end, a total of 264 valid responses were obtained. Data were analyzed using SmartPLS 2.0 beta [21].

\section{RESULTS}

The author first examined construct reliability. All constructs had a value of Cronbach's alpha greater than 0.8 (PAC: 0.820; PFB: 0.830; PCN: 0.938; PTT: 0.865; TIV: 0.886; PEU: 0.886; WTD: 0.881) and a value of Composite Reliability (CR) greater than 0.8 (PAC: 0.893; PFB: 0.898; PCN: 0.960; PTT: 0.917; TIV: 0.929; PEU: 0.921; WTD: 0.926), indicating a considerable level of internal consistency.

Next, the author examined construct validity. Average variances extracted (AVE) of each construct (PAC: 0.736; PFB: 0.745; PCN: 0.890; PTT: 0.787; TIV: 0.814; PEU: 0.744; WTD: 0.807) were above the recommended standards of AVE > 0.5 [22]. The outer loadings of individual items exceeded 0.7 [22] and the $t$-statistics for each outer loading were significant (see Table II). These 
demonstrated an acceptable convergent validity. On the other hand, the square root of each construct's AVE was greater than its correlations with other constructs [23]. This provided support for discriminant validity (see Table III).

TABLE II: OUTER LOADINGS

\begin{tabular}{|c|c|c|}
\hline $\begin{array}{l}\text { Constructs (construct codes) } \\
\text { Item codes }\end{array}$ & $\begin{array}{r}\text { Outer } \\
\text { loadings }\end{array}$ & $t$-statistics \\
\hline \multicolumn{3}{|l|}{ Trust in the VLC (TIV) } \\
\hline TIV1 & 0.904 & $64.750 * *$ \\
\hline TIV2 & 0.925 & $76.153 * *$ \\
\hline TIV3 & 0.877 & $47.693 * *$ \\
\hline \multicolumn{3}{|c|}{ Perceived effectiveness uncertainty (PEU) } \\
\hline PEU1 & 0.824 & $26.580 * *$ \\
\hline PEU2 & 0.891 & $40.325^{* *}$ \\
\hline PEU3 & 0.859 & $31.007 * *$ \\
\hline PEU4 & 0.875 & $43.285^{* *}$ \\
\hline \multicolumn{3}{|l|}{ Willingness to depend (WTD) } \\
\hline WTD1 & 0.899 & $61.024 * *$ \\
\hline WTD2 & 0.915 & $60.806 * *$ \\
\hline WTD3 & 0.879 & $33.409 * *$ \\
\hline \multicolumn{3}{|l|}{ Perceived accreditation (PAC) } \\
\hline PAC1 & 0.877 & $23.197 * *$ \\
\hline $\mathrm{PAC} 2$ & 0.820 & $18.301 * *$ \\
\hline PAC3 & 0.875 & $47.116^{* *}$ \\
\hline \multicolumn{3}{|l|}{ Perceived feedback (PFB) } \\
\hline PFB1 & 0.903 & $61.401 * *$ \\
\hline PFB2 & 0.865 & $33.641 * *$ \\
\hline PFB3 & 0.820 & $27.766 * *$ \\
\hline \multicolumn{3}{|c|}{ Perceived cooperative norms (PCN) } \\
\hline PCN1 & 0.928 & $76.089 * *$ \\
\hline PCN2 & 0.924 & $61.264 * *$ \\
\hline PCN3 & 0.977 & $195.642 * *$ \\
\hline \multicolumn{3}{|l|}{ Propensity to trust (PTT) } \\
\hline PTT1 & 0.922 & $83.146^{* *}$ \\
\hline PTT2 & 0.887 & $37.882 * *$ \\
\hline РTT3 & 0.851 & $34.648 * *$ \\
\hline
\end{tabular}

TABLE III: DISCRIMINANT VALIDITY

\begin{tabular}{lrrrrrrr}
\hline \multicolumn{7}{c}{ Correlations between constructs (the main diagonal shows } \\
& the square root of AVE.) & & & & \\
\cline { 2 - 8 } Constructs & PAC & PCN & PEU & PFB & PTT & TIV & WTD \\
\hline PAC & 0.858 & & & & & & \\
PCN & 0.458 & 0.943 & & & & & \\
PEU & -0.347 & -0.420 & 0.863 & & & & \\
PFB & 0.480 & 0.523 & -0.322 & 0.863 & & & \\
PTT & 0.369 & 0.407 & -0.314 & 0.459 & 0.887 & & \\
TIV & 0.413 & 0.473 & -0.337 & 0.520 & 0.575 & 0.902 & \\
WTD & 0.471 & 0.317 & -0.236 & 0.423 & 0.290 & 0.406 & 0.898 \\
\hline \hline
\end{tabular}

Finally, the author tested the research hypotheses. The parameter estimates demonstrated that among the nine paths analyzed, five were significant $(\mathrm{PAC} \rightarrow \mathrm{PEU}$, $\mathrm{PFB} \rightarrow \mathrm{TIV}, \mathrm{PCN} \rightarrow \mathrm{TIV}, \mathrm{PCN} \rightarrow \mathrm{PEU}$, and $\mathrm{TIV} \rightarrow \mathrm{WTD})$ and four were insignificant $(\mathrm{PAC} \rightarrow \mathrm{TIV}, \mathrm{PFB} \rightarrow \mathrm{PEU}$, $\mathrm{TIV} \rightarrow \mathrm{PEU}$, and $\mathrm{PEU} \rightarrow \mathrm{WTD})$. The results are shown in Fig. 1.

The model explained $44.5 \%$ of the variance of trust in the VLC, $22.1 \%$ of perceived effectiveness uncertainty, and $17.6 \%$ of willingness to depend. Among the three types of control: (1) cooperative norms (clan control) were the strongest predictor of uncertainty $(\beta=-0.26 ; p<0.01)$; (2) feedback (behavior control) was the strongest predictor of trust $(\beta=0.21 ; p<0.01)$; (3) cooperative norms (clan control) had the strongest total effect on learners' willingness to depend on VLC. Learner's trust in the VLC, compared with their perceived effectiveness uncertainty, exhibited a stronger effect on willingness to depend $(\beta=$ $0.37 ; p<0.01)$.

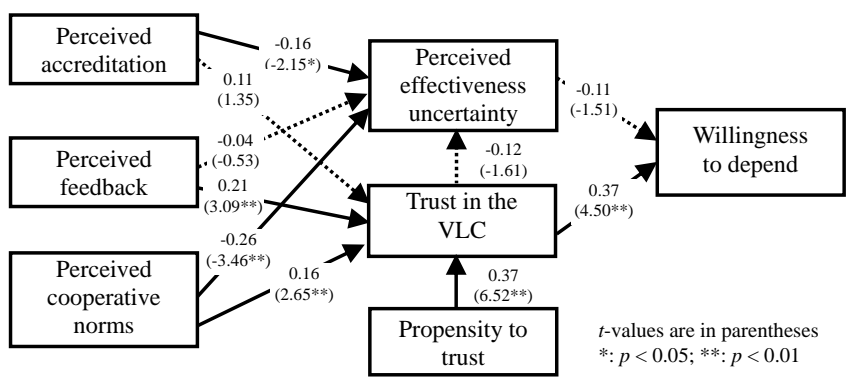

Fig. 1. Results of testing the structural model.

\section{DisCUSSIONS AND CONCLUSIONS}

The results show that even when the effect of propensity to trust on trust is controlled for, cooperative norms and feedback still create trust. Accreditation and cooperative norms reduce learners' uncertainty perception. Learners' trust increases their willingness to depend. However, the effect of accreditation on trust, the effects of trust and feedback on uncertainty perception, and the effect of uncertainty perception on willingness to depend are unconfirmed.

Cooperative norms are shown to be the most significant determinant of learners' perceptions of effectiveness uncertainty. This indicates that, in a VLC, shared values of cooperative learning are the prerequisites. To facilitate the internalization of these values among members, the VLC administration should encourage the members to help each other and to share what they have learned so as to create an atmosphere of collaboration inside the VLC. In addition, the VLC administration should reward those who exhibit cooperative behavior. In an academic context, course credits would be a useful incentive. Other incentives, such as awarding the position of co-administrator and prizes for "poster of the week" and "the best post/comment", could also be useful.

Cooperative norms can be complemented by the feedback mechanism in terms of trust building. It is suggested that a member-driven evaluation system be instituted to provide useful feedback information about member reputation and behavior.

Accreditation influences perceptions of effectiveness uncertainty, suggesting that the VLC administration should invest in screening members' input and filtering inappropriate content out on a regular basis. When it comes to a particular learning subject, the VLC administration should collect useful information, transform it into the form of knowledge, and present it in an acceptable format.

This study is subject to some limitations. First, it did not include as many instances of control as possible. Second, conceptualizing trusting belief as a unitary construct might hinder full understanding about the impact of control on various aspects of trusting belief, such as competence, benevolence, and credibility [19]. Finally, the mostly self-selection sample might jeopardize the generalizability of this study. 
The author thus suggests that further work be carried out, gathering samples from different types of virtual communities and from different national or cultural backgrounds. The author also suggests that further effort be dedicated to identifying and designing other control mechanisms and assessing their effects on learner behavior.

\section{REFERENCES}

[1] C. Romm, N. Pliskin, and R. Clarke, "Virtual communities and society: toward an integrative three phase model," International Journal of Information Management, vol. 17, no. 4, pp. 261-270, 1997.

[2] W. G. Ouchi and M. A. Maguire, "Organizational control: two functions," Administrative Science Quarterly, vol. 20, no. 4, pp. 559-569, 1975.

[3] W. G. Ouchi, "A conceptual framework for the design of organizational control mechanisms," Management Science, vol. 25, no. 9 , pp. $833-848,1979$.

[4] P. A. Pavlou, "Institution-based trust in interorganizational exchange relationships: The role of online B2B marketplaces on trust formation," Journal of Strategic Information Systems, vol. 11, no. 3/4, pp. 215-243, 2002.

[5] T. K. Das, "A multiple paradigm approach to organizational control," The International Journal of Organizational Analysis, vol. 1, no. 4, pp. 385-403, 1993

[1] A. S. Tannenbaum, "Control in organizations: Individual adjustment and organizational performance," Administrative Science Quarterly, vol. 7, no. 2, pp. 236-257, 1962.

[6] P. A. Pavlou and D. Gefen, "Building effective online marketplaces with Institution-based trust," Information Systems Research, vol. 15, no. 1, pp. 37-59, 2004.

[7] F. J. Milliken, "Three types of perceived uncertainty about the environment: State, effect, and response uncertainty," Academy of Management Review, vol. 12, no. 1, pp. 133-143, 1987.

[8] W. R. Scott, Institutions and Organizations, Thousand Oaks, CA: Sage Publication, 1995.

[9] S. Grabner-Kräuter and E. A. Kaluscha, "Empirical research in on-line trust: A review and critical assessment," International Journal of Human-Computer Studies, vol. 58, no. 6, pp. 783-812, 2003.

[10] N. Luhmann, Trust and Power, Chichester, U.K.: Wiley, 1979.

[11] D. Gefen, "E-commerce: The role of familiarity and trust," Omega, vol. 28 , no. 6 , pp. $725-737,2000$.
[12] D. H. McKnight and N. L. Chervany, "What trust means in e-commerce customer relationships: An interdisciplinary conceptual typology," International Journal of Electronic Commerce, vol. 6, no. 2, pp. 35-59, 2001.

[13] S. Jarvenpaa, N. Tractinsky, and M. Vitale, "Consumer trust in an Internet store," Information Technology and Management, vol. 1, no. 1-2, pp. 45-71, 2000.

[14] K. K. Kim and B. Prabhakar, "Initial trust and the adoption of B2C e-commerce: The case of Internet banking," The DATA BASE for Advances in Information Systems, vol. 35, no. 2, pp. 50-64, 2004.

[15] C. M. Ridings, D. Gefen, and B. Arinze, "Some antecedents and effects of trust in virtual communities," Journal of Strategic Information Systems, vol. 11, no. 3-4, pp. 271-295, 2002.

[16] D. H. McKnight, V. Choudhury, and C. Kacmar, "The impact of initial consumer trust on intentions to transact with a web site: A trust building model," Journal of Strategic Information Systems, vol. 11, no. 3-4, pp. 297-323, 2002.

[17] P. Bordia, E. Hunt, N. Paulsen, D. Tourish, and N. DiFonzo, "Uncertainty during organizational change: Is it all about control?" European Journal of Work and Organizational Psychology, vol. 13, no. 3, pp. 345-365, 2004.

[18] D. H. McKnight, V. Choudhury, and C. Kacmar, "Developing and validating trust measures for e-commerce: An integrative typology," Information Systems Research, vol. 13, no. 3, pp. 334-359, 2002

[19] J. B. Heide and G. John, "Do norms matter in marketing relationships," Journal of Marketing, vol. 56, no. 2, pp. 32-43, 1992.

[20] C. M. Ringle, S. Wende, and A. Will. (June 2010). SmartPLS Version 2.0 beta. [Online]. Available: http://www.smartpls.de.

[21] J. F. Hair Jr., R. E. Anderson, R. L. Tatham, and W. C. Black, Multivariate Data Analysis, 5th ed., Englewood Cliffs, NJ: Prentice Hall, 1995.

[22] C. Fornell and D. F. Larcker, "Evaluating structural equation models with unobservable variables and measurement error," Journal of Marketing Research, vol. 18, no. 1, pp. 39-50, 1981.

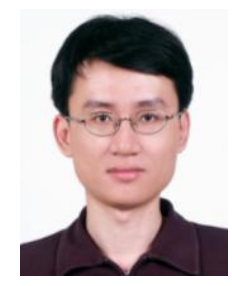

Ying-Wei Shih was born in Taiwan. He received a Ph.D. degree in MIS from National Chengchi University in Taipei, Taiwan. He is currently an Associate Professor in the Department of Information Management at National Changhua University of Education, Changhua, Taiwan. His research interests focus mainly on e-commerce, e-learning, mobile value-added services, and information service industry. 